Quebec Cooperative Study

of Friedreich's Ataxia

\title{
Computed Tomography of Posterior Fossa in Hereditary Ataxias
}

\author{
R. LANGELIER, J.P.BOUCHARD AND R.BOUCHARD
}

SUMMARY: Nine cases of Friedreich's ataxia and seven cases of autosomal recessive spastic ataxia of CharlevoixSaguenay (ARSACS) were submitted to neuroradiological procedures to determine the extent of atrophic processes in the central nervous system. All cases had a computerized cerebral tomography and five were studied with pneumencephalography. The results show a correlation

RÉSUME: Nous avons procédé à des épreuves neuroradiologiques dans neuf cas d'ataxie de Friedreich et dans sept cas d'ataxie spastique familiale de CharlevoixSaguenay (ARSACS) pour évaluer l'importance et la distribution de l'atrophie au niveau du système nerveux central. Une tomographie axiale cérébrale par ordinateur a été pratiquée dans tous les cas, et cinq patients ont été soumis à une pneumonencéphalographie. Les résultats montrent une bonne corrélation entre les between the two tests and the comparison between Friedreich's ataxia and ARSACS.

In Friedreich's ataxia, the radiological signs are variable and discrete in most of the cases. In ARSACS there are constant signs of cerebellar atrophy almost limited to the superior parts of the vermis and anterior lobes.

deux épreuves et permettent une comparaison entre ces deux formes d'ataxie retrouvées au Québec.

En effet, dans l'ataxie de Friedreich, les signes radiologiques sont variables et plutôt discrets dans la plupart des cas. Dans l'ataxie spastique (ARSACS) on retrouve des signes constants d'atrophie cérébelleuse pratiquement limitée à la partie supérieure du vermis et des lobes antérieurs.
From L'Hôpital de l'Enfant-Jésus, Quebec City.

Reprint requests for the complete supplement on Friedreich's ataxia (Phase Two, Part Two) to:

Dr. André Barbeau, Clinical Research Institute of Montreal, 110 Pine Avenue West, Montreal, Quebec. Canada, H2W IR7.
INTRODUCTION
Pneumoencephalography (PEG) has been recognized as the best procedure to determine the extent and selectivity of atrophic processes in the central nervous system. Stricto sensu, $P$ E G refers to the use of gas as a contrast medium to visualise the brain and surrounding structures, radiologically. Historically the first, it is also the most invasive technique to achieve this goal.

In the hereditary ataxias, the clinical picture provides the most important diagnostic clue, since ancillary tests rarely help to classify the numerous and variable types of the disease (Tyrer, 1975). Except for olivopontocerebellar atrophy, the P E G and pathological changes are not really specific and may at best explain some peculiarities of the syndromes. Computed tomography (CT) improves the investigation of the posterior fossa in ataxic patients by:

- identification of tumors and evaluation of their position and size.

- showing atrophy of certain important structures with as good a correlation as PEG.

In this paper, we intend to assess the value of CT scan of the posterior fossa in two heredo-degenerative disorders that we have studied in the Québec Cooperative Study: Friedreich's ataxia and the autosomal recessive spastic ataxia of Charlevoix-Saguenay (ARSACS) described in 1978 (Bouchard et al. 1978).

\section{SUBJECTS AND METHODS}

Sixteen patients were submitted to neuroradiological investigation for hereditary ataxia. Nine patients presented with disease meeting the criteria of Friedreich's ataxia (Tyrer, 
1975, Geoffroy et al., 1976) and form Group I. Seven patients with a slowly progressive and less severe syndrome of ARSACS (Bouchard et al. 1978) form Group II. Five patients were previously investigated with PEG and those five and the eleven others were submitted to CT scan. Their distribution according to age, clinical group, and neuroradiological investigation is given in Table $\mathrm{I}$.

The PEGs were performed under general anaesthesia on a neurodiagnostic (Philips) unit. We obtained lateral tomograms on every patient in order to evaluate the cisterna magna, the superior and inferior vermis, the IVth ventricle, the pons, and the confluence of the dorsal communicating cisterns, especially Galen, quadrigeminal, and supra-vermian cisterns (GQVC).

The CT scan (on EMI 5005) of the posterior fossa was done the usual way, i.e. with four $13 \mathrm{~mm}$. thick plain cuts at $10 \mathrm{~mm}$ intervals, which is the standard procedure in our department. Using this approach allowed us to compare these examinations with other normal posterior fossa scans and to look for signs consistent with cerebellar atrophy. Thereafter, we made the comparison between PEG and CT for the five patients evaluated by the two methods.

Based on accumulated data from normal examinations of the posterior fossa, we have retained three signs of vermian atrophy:

1. Enlargement of superior cerebellar sulci (SCS) (Fig. 1).

2. Increased volume of cisterna magna and vallecula (CMV) (Fig. 2).

3. Enlargement of GQVC (Fig. 3), which is a more subtle sign is clearly enlarged and diamond shaped in some cases.

Although we did not think that they were of great importance, we have included the following measurements:
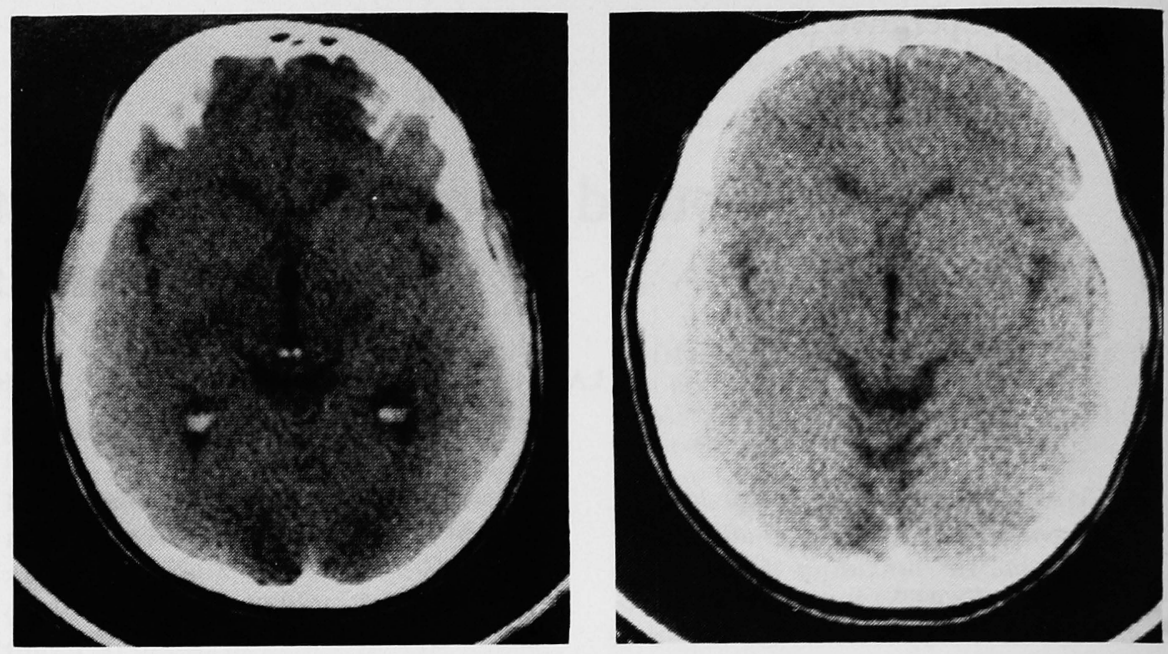

Figure 1 - The superior cerebellar sulci are not seen in normal CT scan (a). In (b) there is marked midline cerebellar atrophy and the superior sulci are enlarged in a case of ARSACS.
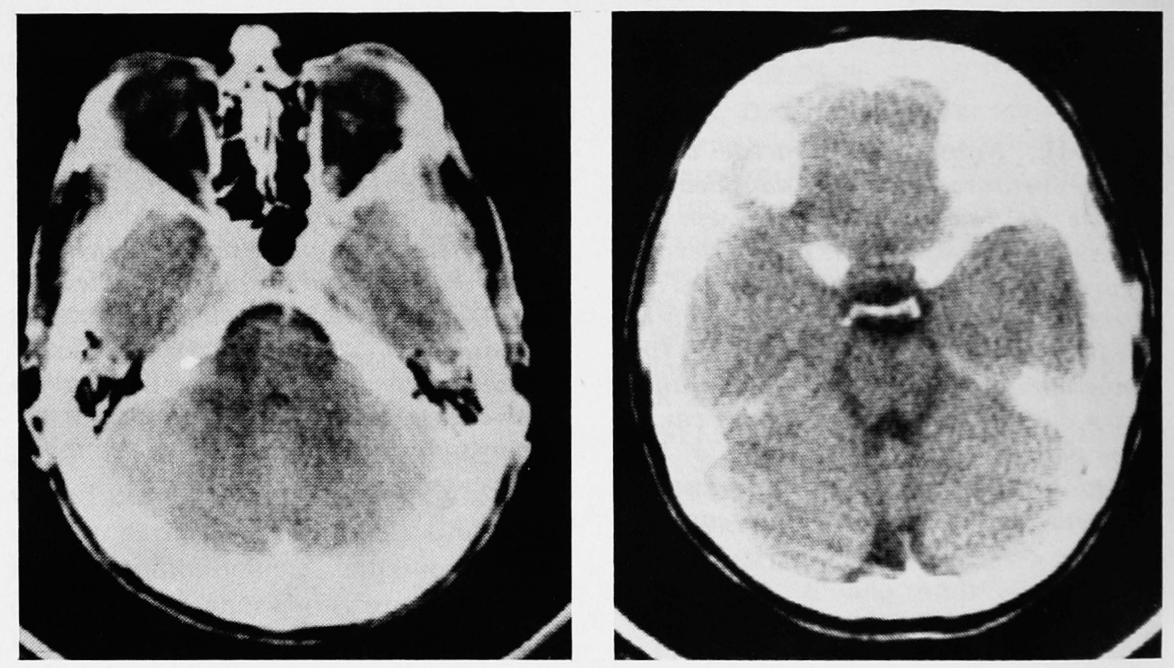

Figure 2 - In normal CT scan, the vallecula and cisterna magna are not visualized (a). These cisterns are large (b) in the same patient as the previous figure.

4. Volume of the IVth ventricle.

5. Width of the pons.

\section{RESULTS}

\section{CTSCAN}

In Group I, although the patients were clinically more affected, the scan

TABLE 1

\begin{tabular}{lcccccc}
\hline & \multicolumn{2}{c}{ Group I } & \multicolumn{2}{c}{ Group II } \\
& N & Mean Age & (Range) & N & Mean Age & (Range) \\
\hline & 2 & 18.5 & $(18-19)$ & 3 & 29.0 & $(20-36)$ \\
PEG \& CT & 7 & 20.0 & $(6-28)$ & 4 & 25.7 & $(18-30)$ \\
CT only & 9 & 19.2 & $(6-28)$ & 7 & 27.1 & $(18-36)$ \\
TOTAL & & &
\end{tabular}



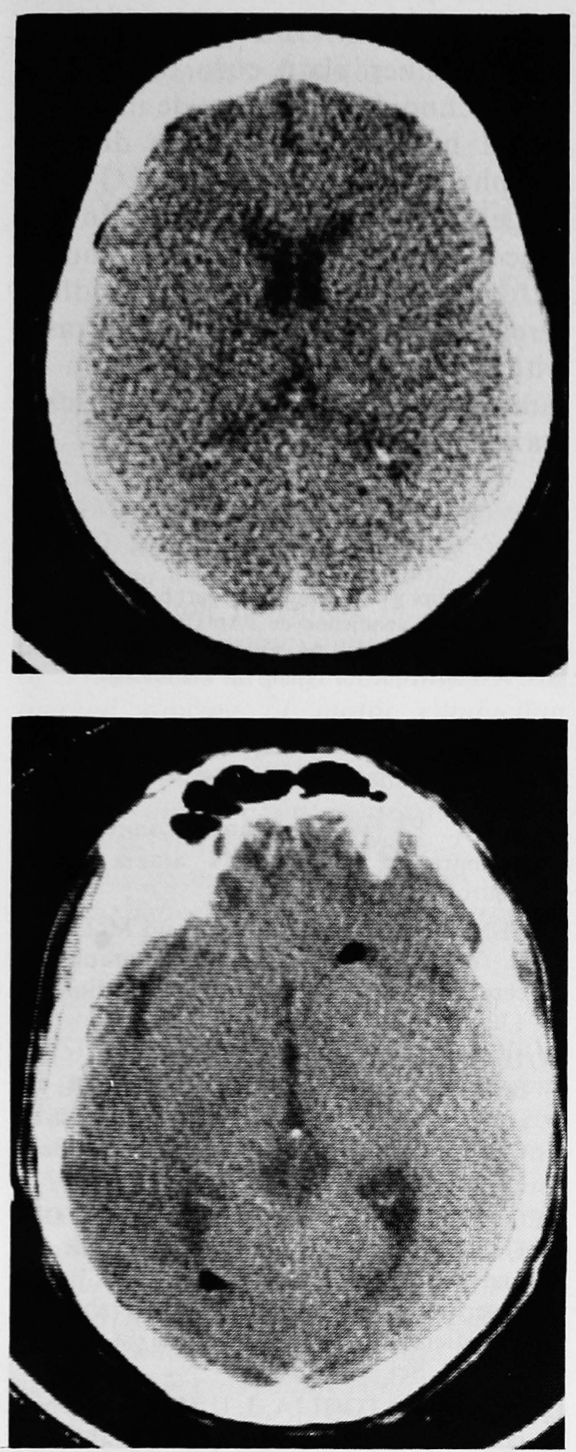

Figure 3-These pictures show a normal (a) triangular shaped GQVC in a case of ARSACS and an enlarged diamond shaped (b) GQVC in a case of Friedreich's ataxia. The latter picture is about $10 \mathrm{~mm}$ lower and shows residual air in right frontal and left occipital horns.

In Group II, none of the seven patients had a normal CT scan. In six cases, the SCS were well seen and found markedly enlarged on one occasion. Enlargement of CMV was obvious in four cases. Three patients had huge GQVC, but of those, only one had an increased CMV. The only patient with normal SCS was noted to have a large IVth ventricle and a small pons. The oldest patient of this group presented with moderate diffuse cerebral atrophy as well.

As seen in Table II, patients with Friedreich's ataxia show little evidence of cerebellar atrophy, unlike ARSACS (Group II), two exhibited moderate atrophy of the superior vermis (Fig. 4), without clear evidence of atrophy in other cerebellar and midbrain structures and the other showed moderate and diffuse cerebellar and cerebral atrophy.

\section{Correlation PEG/CT Scan}

In Table III the signs found by PEG or CT for each of the five patients submitted to both procedures are shown. The correlation was found excellent in four cases and fair, but not misleading, in one (Case 3 ).

\section{DISCUSSION}

When we undertook this study, there were few data on CT use in evaluation of the posterior fossa in hereditary ataxia. Several papers have been published recently (Maruyama et al., 1977; Aita, 1978; Lee et al., 1978; Allen et al., 1979) and the authors have found CT to be a valuable tool for the evaluation of cerebellar and pontine atrophy. However, only one case was clearly identified as Friedreich's ataxia and showed a normal CT scan (Maruyama, 1977). Aita (1978) reported one case of Marie's ataxia and found a small pons with increased IVth ventricle and cisterns. Lee et al. (1978) and Allen et al. (1979) have confirmed the variation of findings in a total of 23 patients with unspecified forms of hereditary ataxia.

A comparison of PEG and CT was made by Lee et al. (1978), who found good correlation in 70 to $80 \%$ of the cases for each of the following parameters: size of the IVth ventricle, cerebellar cortical sulci, cisterns of the posterior fossa.

TABLE II

\begin{tabular}{lcc}
\hline \multicolumn{1}{c}{ CT Scan } & Group I & Group II \\
\hline Radiological Signs & Friedreich's Ataxia & ARSACS \\
& N:9 $: 7$ \\
\hline I Superior Cer. Sulci & 1 & 6 \\
t Cisterna Magna and Vallecula & 1 & 4 \\
t GQVC & 1 & 3 \\
IIVth Ventricle & 2 & 1 \\
I Pons & 1 & 0 \\
\hline Normal CT Scan & 4 & 1 \\
\hline
\end{tabular}

TABLE III

CT/PEG Correlation

\begin{tabular}{|c|c|c|c|c|c|}
\hline \multirow[b]{2}{*}{ CT Scan } & \multicolumn{2}{|c|}{ Group I (FA) } & \multicolumn{3}{|c|}{ Group II (ARSACS) } \\
\hline & case 1 & case 2 & case 3 & case 4 & case 5 \\
\hline isCS & - & - & + & + & + \\
\hline † CMV & - & - & + & + & + \\
\hline १GQVC & + & - & - & - & + \\
\hline I IVth & + & - & - & - & - \\
\hline ! Pons & - & - & - & - & - \\
\hline \multicolumn{6}{|l|}{ PEG } \\
\hline isCS & - & - & + & + & + \\
\hline $1 \mathrm{CMV}$ & - & - & - & + & + \\
\hline † GQVC & - & - & + & - & + \\
\hline IIVth & + & - & - & - & - \\
\hline ! Pons & - & - & - & - & - \\
\hline
\end{tabular}




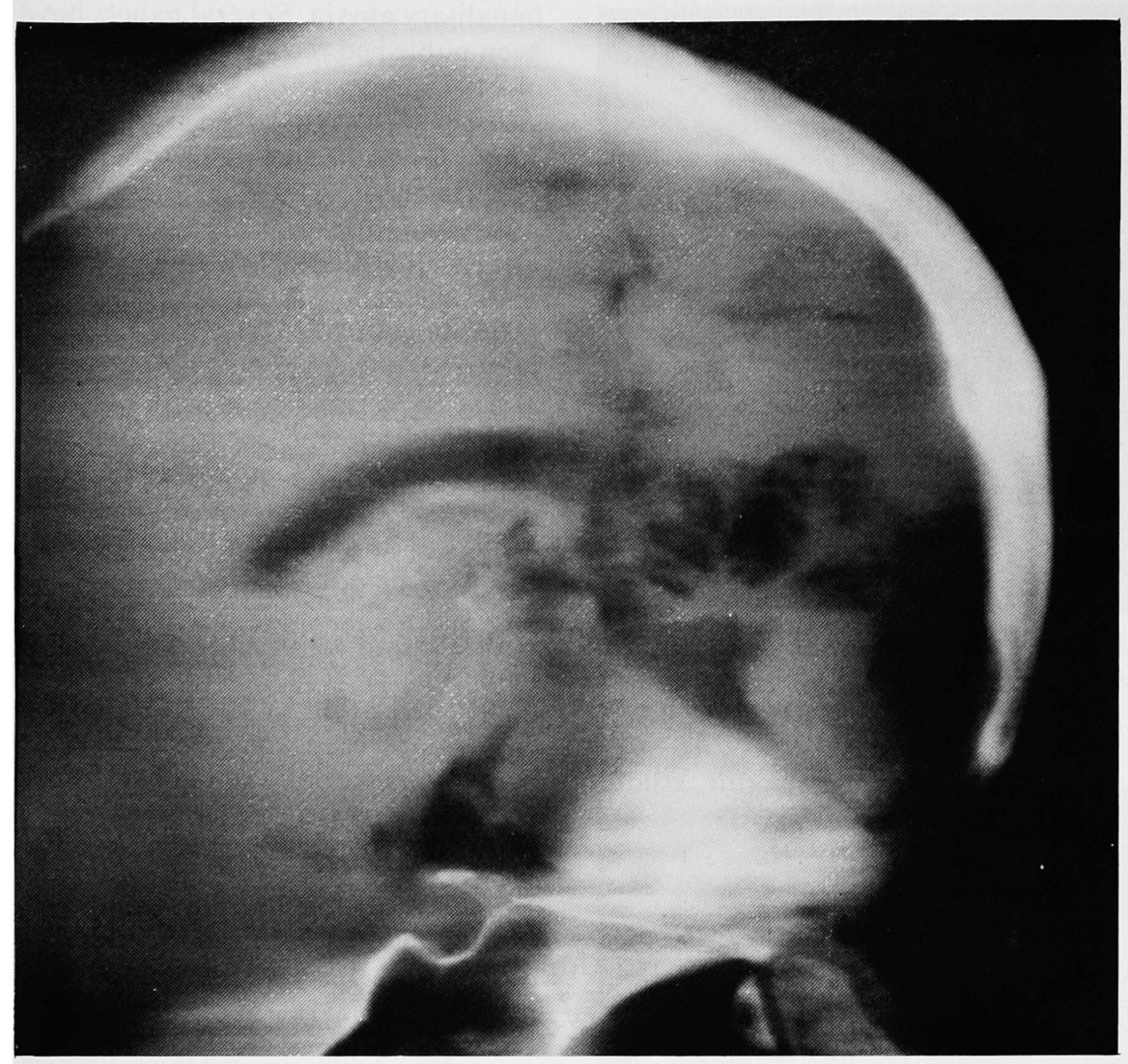

Figure 4-The picture shows marked selective atrophy of the superior vermis and a huge cisterna magna in a case of ARSACS. The IVth ventricle, the inferior vermis and the pons are normal.

Allen et al. (1979) emphasized the enlargement of the superior cerebellar cistern (which we have called GQVC because of the confluence of cisterns at this level) but noted a wide normal variation in the size and shape of that cistern with CT. It is so important in some of our cases that we think it is a valuable sign. We noted that the most frequent sign of vermian atrophy on PEG was the enlargement of GQVC. Thinner cuts would improve the evaluation of GQVC and will be made in the future with 5 and $10 \mathrm{~mm}$ collimators.

In Friedreich's ataxia, PEG and CT show no constant or typical signs and correlate well with the subtleness and easily detected even with standard cuts. Thinner plain cuts and use of subarachnoidal metrizamide injection would help to demonstrate discrete atrophy of the cerebellum. PEG is no longer indicated in these cases. In this series, ARSACS patients have shown a constant and marked midline cerebellar atrophy which contrasts with the subtleness and variation of radiological signs in Friedreich's ataxia.

\section{ACKNOWLEDGEMENTS}

These studies were supported in part by a grant from l'Association Canadienne de l'Ataxie de Friedreich. Thanks are due to Dr. M. Delisle for his advice and Mrs. A. Labrecque for typing the manuscript.

\section{REFERENCES}

AITA, J. F. (1978). Cranial computerized tomography and Marie's ataxia. Arch. Neurol., 35, 55-56.

ALLEN, J. H., MARTIN, J. T. and McLAIN, L. W. (1979). Computed tomography in cerebellar atrophic processes. Radiology, 130, 379-382.

BOUCHARD, J. P., BARBEAU, A. BOUCHARD, R. and BOUCHARD, R. W. (1978). Autosomal recessive spastic ataxia of Charlevoix-Saguenay. Can. J. Neurol. Sci., 5, 61-69.

GEOFFROY, G., BARBEAU, A., BRETON, G., LEMIEUX, B., AUBE, M., LEGER, C., and BOUCHARD, J. P. (1976). Clinical description and roentgenologic evaluation of patients with Friedreich's ataxia. Can. J. Neurol. Sci., 3, 279-286.

LEE, S. H. and TOGLIA, J. U. (1978). Cerebellar atrophy: Pneumoencephalography and computerized tomography correlation. Neuroradiology, 16, 179-180.

MARUYAMA, S. (1977). Examination of spinocerebellar degenerative patients by computerized tomography. In: Research Group on spinocerebellar Degeneration (Japan), pp 119-129. Report No. I

NETSKY, M. G. (1968). Degenerations of the cerebellum and its pathways. In: Pathology of the nervous system. Munckler, J. (editor). McGraw-Hill, New York, Vol. I, pp 1163 1185

TYRER, J. H. (1975). Friedreich's ataxia In: Handbook of Clinical Neurology. P. J. Vinken and G. W. Bruyn, editors. North Holland Publ. Co., Amsterdam. Vol. 21., 319-364. 